\title{
Diffusion Releases Through One and Two Finite Planar Zones \\ From a Nuclear Waste Package
}

\author{
T. S. Ueng \\ W. J. O'Connell
}

\section{Lawrence Livermore National Laboratory}

Publication Date: July 1992

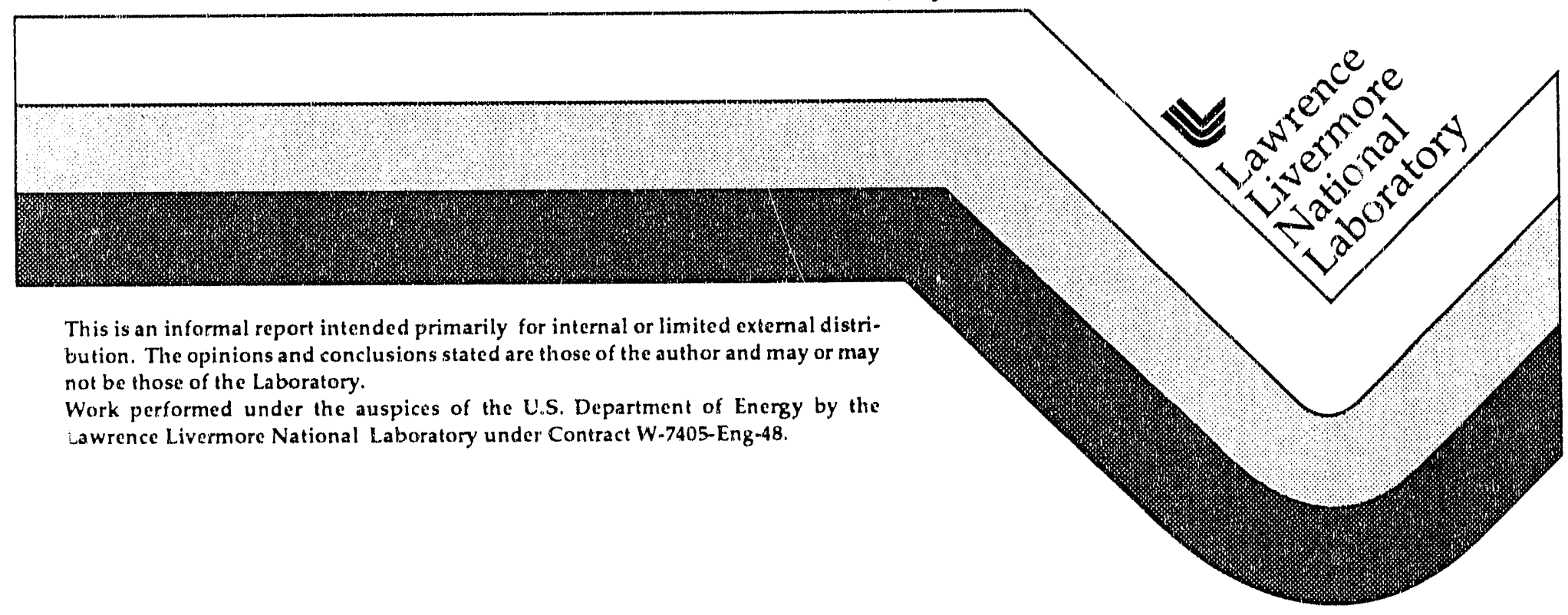




\section{DISCLAIMER}

This document was prepared as an acccount of work sponsored by an agency of the United States Government. Neither the United States Government nor the University of California nor any of their employees, makes any warranty, express or implied, or assumes any legal tiability or responsibility for the accuracy, completeness, or usefulness of any information, apparatus, product, or process disclosed, or represents that its use would not intringe privatelv own rights Reference herein to any specific commercial products, process, or service by trade name, trademark, rnanutacturer, or otherwise, does not necessarily constitute or imply its endorsement, recommendation, or favoring by the United States Government or the University of California. The views and opinions of authors expressed herein do not necessarilv state or reflect those of the United States Government or the University of California, and shall not be used for advertising or product endorsement purposes.

This report has been reproduced directly from the best available copy.

Available to DOE and DOE contractors from the Office of Scientific and Technical Information

P.O. Box 62, Oak Ridge, TN 37831

Prices available from (615) 576-8401, FTS 626-8401

Available to the public from the National Technical Information Service

U.S. Department of Commerce 5285 Port Roval Rd., Springfield, VA 22161

Prepared by Yucca Mountain Site Characterization Project (YMP) participanis as part of the Civilian Radioactive Waste Management Program. The YMP is managed by the Yucca Mountain Site Characterization Project Office of the U.S. Department of Energy, Las Vegas, Nevada. 


\title{
DIFFUSION RELEASES THROUGH ONE AND TWO FINITE PLANAR ZONES FROM A NUCLEAR WASTE PACKAGE
}

\author{
Tzou-Shin Ueng and William J. O'Connell \\ Lawrence Livermore National Laboratory \\ Livermore, CA 94550
}

UCRL-ID--109215

DE92 016744

\begin{abstract}
For a radioactive waste package emplacement in a potential repository, a partially saturated rock rubble zone may act more as a diffusive barrier than as a pathway to release. We approximate the diffusive transport from the waste package using onedimensional one and two-barrier geometries. When the effective diffusion coefficient in the first zone is several orders of magnitude lower than that in the host rock, then the two-zone geometry can be approximated by a one-zone problem, keeping only the narrow rubble zone. When the effective diffusion coefficients in the two zones are comparable, or there is an additional barrier, then a two-zone (both of finite extent) approach is adopted. We present solutions for the diffusion response in the two planar geometries for three input cases: a pulse transient input, a steady input rate, and a constant concentration ai the source. The solutions have algebraic key elements allowing identification of sensitive factors. For the one-zone case, dimensionless parameters allow plotting of the family of transient response solutions on a single graph. Comparisons with several problems analyzed by others, and on problems where the one-zone and two-zone analyses should give comparable results, support verification of the method.
\end{abstract}

\section{INTRODUCTION}

NRC regulation ${ }^{1}$ requires that release rates of radionuclides from the engineered barrier system (EBS) be limited. Diffusion can provide transport on the EBS scale even if there is no advection, but at a partially saturated site the amplitude of diffusion might be quite limited. Recent experiments by Conca $^{2}$ showed that the effective diffusion coefficient in a partially saturated rubble backfill of tuff rock can be orders of magnitude lower than that in pure water. Thus a rubble zone between the waste package and the borehole wall is potentially a barrier for the diffusive release of radionuclides from the waste package. Early analysis 3 of this situation indicated a high benefit from a rubble zone for a radionuclide with a high retardation factor. This prompted studies in using diffusive barriers to limit the radionuclide releases.

Various geometric approximations have been used for the waste package, near field, diffusion-advection problems. ${ }^{4,5}$ These include spherical, cylindrical, and planar geometries, and a prolate spheroid waste package. All the geometries should give similar results at early times in a transient, when only a region near the waste package surface is effectively involved. At late times the geometry will make a difference in the results. We are interested in the maximum release rates which would likely occur at early times. Considering the relative narrow rubble zone $(\approx 3 \mathrm{~cm})$ with a large waste 


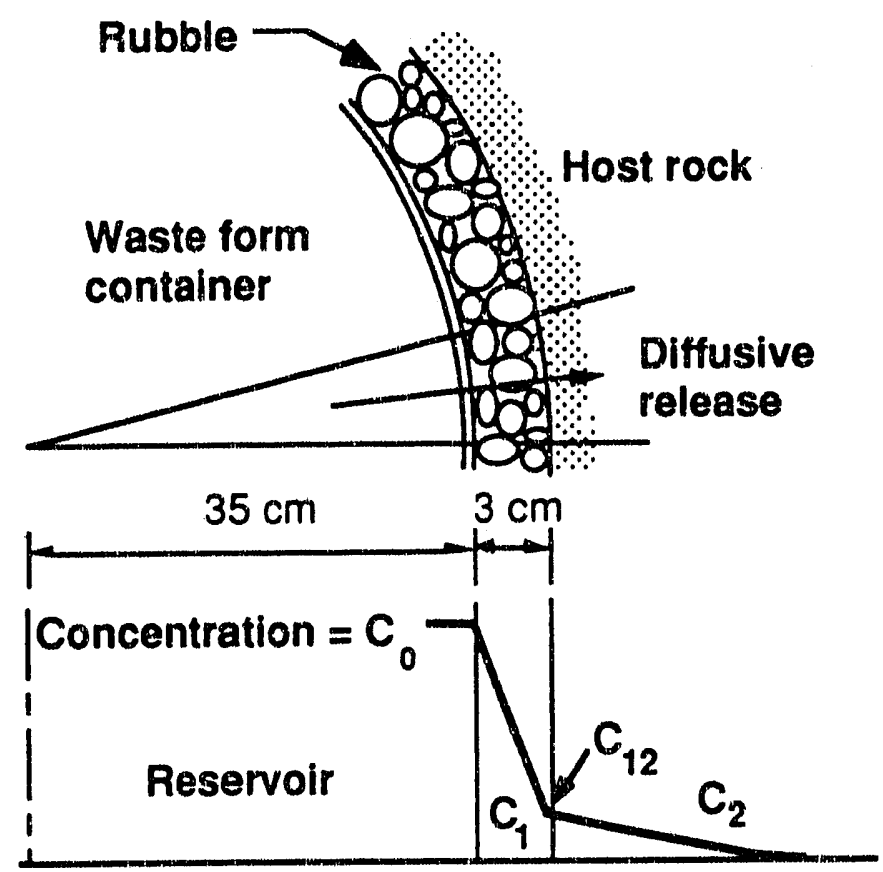

Figure 1. One-dimensional approximation of diffusion release from waste package.

package diameter $(\approx 70 \mathrm{~cm})$ as shown in Fig. 1, it can be justified that the near field diffusion problem can be approximated by a one-dimensional problem.

Recent analytical work by Pigford and coworkers6,' provided solutions for the transient diffusion problems in a series of two planar zones, one a rubble zone and the other an intact partially saturated host rock zone of semi-infirite extent. Due to the complexity of the solutions, some simplifications were made in their implementation ${ }^{6}$, and the parameter and sensitivity studies using the solutions required a considerable effort.

In order to facilitate parameter and sensitivity studies for design and performance of the waste package, we consider the low-diffusion rubble zone problem as a one-zone problem, i.e., the rubble zone only, neglecting the diffusive resistance of the rock zone exterior to it. The simplification is possible with fairly good accuracy because of the much higher diffusion resistance in the rubble zone than in the host rock. This will give more conservative results for the near field diffusive release of radionuclides.

A rubble zone is actually only one part of a complicated pathway for diffusion from a waste form to the surrounding host rock. The water pathway must extend through some breaches in the waste container and fuel cladding to contact the spent fuel waste. At a partially saturated site this pathway would most likely be a thin water 
film on the material surfaces. To add another one of these pathway elements to the conceptual model as an additional diffusive barrier, we developed solutions for the transient diffusion problems across two planar zones, both of finite extent. The twozone solution can also be used to verify the accuracy of the one-zone solution.

Three cases of radionuclide sources giving different boundary conditions are analyzed: (1) a constant concentration at the source for solubility limited radionuclides, (2) a transient pulse input of the rapid release portion of a radionuclide from the fuelcladding gap, voids, and grain boundaries, and (3) a steady input rate congruent with the waste-matrix alteration until exhaustion of the matrix. The decay of the radionuclides with time is not considered, but can be readily included in the solutions.

\section{SINGLE DIFFUSIVE BARRIER ANALYSIS}

We assume the following waste behavior as the basis of the inner boundary conditions. When the waste container has breached and ground water penetrates into the waste package, there is immediate dissolution of the rapidly available fraction of soluble species into the volume of water inside the container. The volume of water is best estimated as that of a water film on the spent fuel surface. The waste matrix begins altering, releasing radionuclides to water at a steady rate. Low-solubility radionuclides reach their concentration limit immediately. The solution is well mixed and is in contact with the inner edge of the rubble zone. We are assuming there is no retardation inside the container.

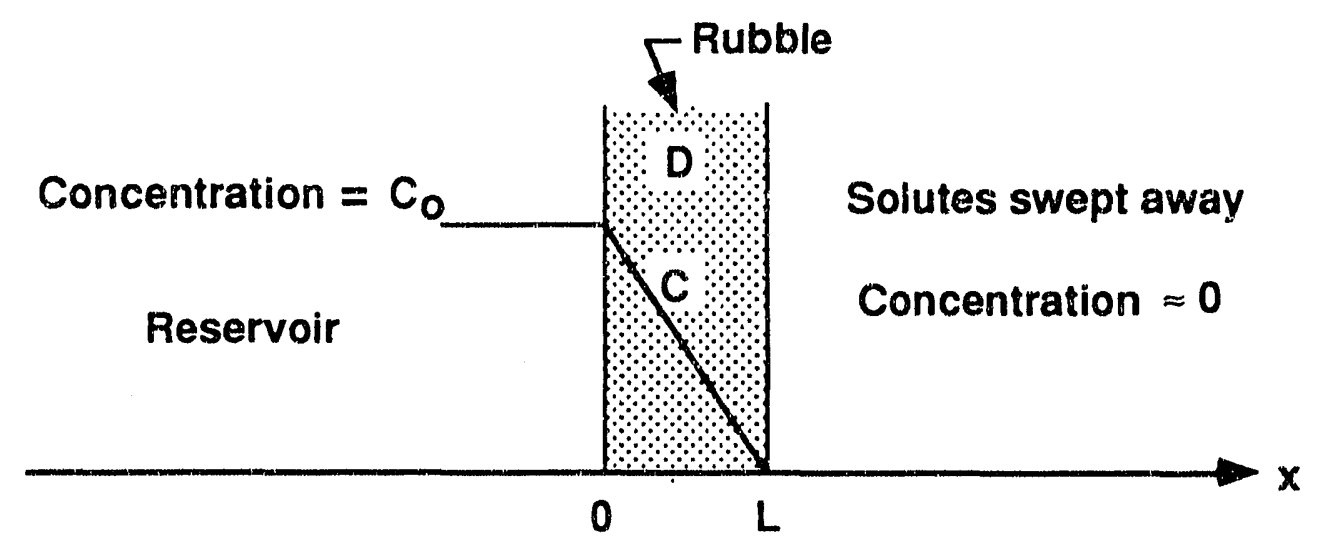

Figure 2. One-dimensional one-barrier diffusion analysis in Fig. 2 is

The basic diffusion equation for a one-dimensional one-zone problem as shown

$$
R \frac{\partial C(x, t)}{\partial t}=D \frac{\partial^{2} C(x, t)}{\partial x^{2}}, \quad t>0, L>x>0
$$


where $C(x, t)=$ the concentration of the radionuclide within the barrier,

$x=$ the distance from the outer boundary of the waste package,

$t=$ time since water contact,

$L=$ thickness of the diffusive barrier,

$D=$ the species effective diffusion coefficient in the diffusive barrier, and

$\mathrm{R}=$ the retardation coefficient.

\section{Constant Concentration Source}

For a constant concentration, $\mathrm{C}_{\mathrm{s}}$, at the source due to the limited solubility of the radionuclide, the initial and boundary conditions are:

$$
\begin{array}{ll}
C(x, 0)=0, & x>0 \\
C(0, t)=C_{0}=C_{S}, & t \geq 0 \\
C(L, t)=0, & t \geq 0
\end{array}
$$

We use the conventional method of separation of variables for the solution of $C(x, t)$.

Then the mass release rate at the borehole wall is

$$
\begin{aligned}
& f_{c}=-a D \frac{\partial C}{\partial x} \text { at } x=L, \\
& f_{c}=\frac{a D C_{s}}{L}\left(1+2 \sum_{m=1}^{\infty} e^{-D m^{2} \pi^{2} t / R L^{2}} \cos m \pi\right)
\end{aligned}
$$

where $a=$ area for the diffusion process $=A \varepsilon$

$A=$ the total surface area of the container

$\varepsilon=$ water-filled porosity of the rubble

\section{Transient Pulse Source}

For a transient pulse input, i.e., a dirac delta function, of the rapid release portion of a radionuclide, the initial and boundary conditions are

$$
\begin{aligned}
& C(0,0)=C_{0}=\frac{Q_{r}}{V} \\
& C(x, 0)=0, \quad x>0 \\
& C(L, t)=0, \quad t \geq 0
\end{aligned}
$$

where $Q_{r}=$ mass of the rapid release portion and $V=$ yolume of water in the container. in addition a mass balance relation at the interface between the waste package and the rubble zone equates the mass change rate of radionuclide in the container and the mass flux into the rubble through the area, $a$.

$$
-V \frac{\partial C}{\partial t}=-a D \frac{\partial C}{\partial x}, \quad \text { at } x=0, t>0
$$


Taking a Laplace transform with respect to $t$, and using the expansion theorem for the inversion of Laplace transform as illustrated in Appendix, we can obtain the following solution for the mass release rate at the borehole wall $(x=L)$ :

$$
f_{r}=\frac{2 a D Q_{r}}{V L} \sum_{n=1}^{\infty} B_{n} e^{-D \mu_{n}^{2} t / R L^{2}}
$$

where $B_{n}=\frac{\mu_{n}}{\left(1+\alpha+\mu_{n}^{2} / \alpha\right) \sin \mu_{n}}$

$$
\begin{aligned}
& \alpha=\frac{\operatorname{RaL}}{\mathrm{V}} \\
& \mu_{\mathrm{n}}=\mathrm{nth} \text { root of the characteristic equation, } \\
& \qquad \mu=\alpha \cot \mu
\end{aligned}
$$

We can see $\alpha=(R \times$ volume of water in the rubble backfill) / (volume of water in the container).

\section{Steady Source Congruent with Waste-matrix Alteration}

For alteration-controlled release of radionuclides, we consider the altered mass per unit time, $q_{a}$, as a continuous pulse input, and do a time convolution of the pulse release in Eq. (3). Letting $\mathrm{f}_{\mathrm{q}}$ be the solution in Eq. (3) for a pulse input $\mathrm{q}_{\mathrm{a}} \mathrm{d} \tau$ in place of $\mathrm{Q}_{\mathrm{r}}$, and assuming that the steady input at rate $\mathrm{q}_{\mathrm{a}}$ continues from time 0 to $\mathrm{t}_{\mathrm{e}}$ and is zero thereafter, then the alteration-controlled release rate at the borehole wall before the exhaustion of inventory of the radionuclide, i.e., $t \leq$ time of inventory exhaustion, $t_{e}$, is

$$
\begin{aligned}
f_{a}(t) & =\frac{2 a D q_{a}}{V L} \int_{0}^{t} \sum_{n=1}^{\infty} B_{n} e^{-D \mu_{n}^{2}(t-\tau) / R L^{2}} d \tau \\
& =2 \alpha q_{a}\left[\sum_{n=1}^{\infty} \frac{B_{n}}{\mu_{n}^{2}}\left(1-e^{-D \mu_{n}^{2} t / R L^{2}}\right)\right]
\end{aligned}
$$

For $\mathrm{t} \geq \mathrm{t}_{\mathrm{e}}$

$$
\begin{aligned}
f_{a}(t) & =\frac{2 a D q_{a}}{V L} \int_{0}^{t_{0}} \sum_{n=1}^{\infty} B_{n} e^{-D \mu_{n}^{2}(t-\tau) / R L^{2}} d \tau \\
& =2 \alpha q_{a}\left[\sum_{n=1}^{\infty} \frac{B_{n}}{\mu_{n}^{2}}\left(e^{-D \mu_{n}^{2}\left(t-t_{e}\right) / R L^{2}}-e^{-D \mu_{n}^{2} t / R L^{2}}\right)\right]
\end{aligned}
$$

The solutions in Eqs. (2) - (6) have algebraic key elements allowing identification 
of sensitive factors in computing the radionuclide release rate. This is discussed in the next section.

\section{DIMENSIONLESS PRESENTATION FOR PARAMETER STUDY}

In Eqs. (2) - (6), there are several variables that will affect the radionuclide release rate from the waste package. Some are properties of the radionuclide $\left(C_{S}, Q_{r}\right.$ and $\left.q_{a}\right)$, some are properties of the surrounding environment ( $a, D$, and $R$ ), and some are design inputs ( $V$ and $L$ ). In order to facilitate the parameter and sensitivity studies for design, two dimensionless parameters, $\alpha=a L R / V$ as used above and $T=D t / R L^{2}$, are introduced. The Eqs. (2), (3), (5) and (6) can then be rewritten as follows:

For constant concentration source:

$$
\frac{f_{c} t}{C_{s} V}=\alpha T\left(1+2 \sum_{m=1}^{\infty} e^{-m^{2} \pi^{2} T} \cos m \pi\right)
$$

For transient pulse release:

$$
\frac{f_{r} t}{Q_{r}}=2 \alpha T \sum_{n=1}^{\infty} B_{n} e^{-\mu_{n}^{2} T}
$$

For alteration-controlled release:

$$
\begin{aligned}
& \frac{f_{a}}{q_{a}}=2 \alpha \sum_{n=1}^{\infty} \frac{B_{n}}{\mu_{n}^{2}}\left(1-e^{-\mu_{n}^{2} T}\right), t \leq t_{e} \\
& \frac{f_{a}}{q_{a}}=2 \alpha \sum_{n=1}^{\infty} \frac{B_{n}}{\mu_{n}^{2}}\left(e^{-\mu_{n}^{2}\left(1-\frac{t_{e}}{t}\right) T}-e^{-\mu_{n}^{2} T}\right), t \geq t_{e}
\end{aligned}
$$

Thus, the release rates for various design conditions of the engineered barrier system can be given by Eqs. (7) - (10) in terms of two dimensionless parameters, $\alpha$ and $T$. The parameter and sensitivity studies can be conducted by varying the values of $\alpha$ and $\mathrm{T}$.

For example, Eqs. (8) and (9) can be represented by the family of curves in Figs. 3 and 4 . From these charts, we can obtain the release rate of the radionuclides from the rapid release fraction at any time and the waste-matrix alteration-controlled release at any time before inventory exhaustion, and under any combination of design conditions, such as container volume, diffusion barrier dimensions, and diffusivity and retardation of the barrier material. Figs. 3 and 4 show that for higher values of $\alpha(>10)$, there is approximately a single functional shape for the curves. Fig. 3 also indicates that the peak value of (release rate $\times$ time / rapid release fraction) is approximately a constant for all values of $\alpha$. That is, the peak release rate is inversely proportional to time of reaching the peak release. Furthermore, if we consider the "breakthrough time", $t_{b}$, for 


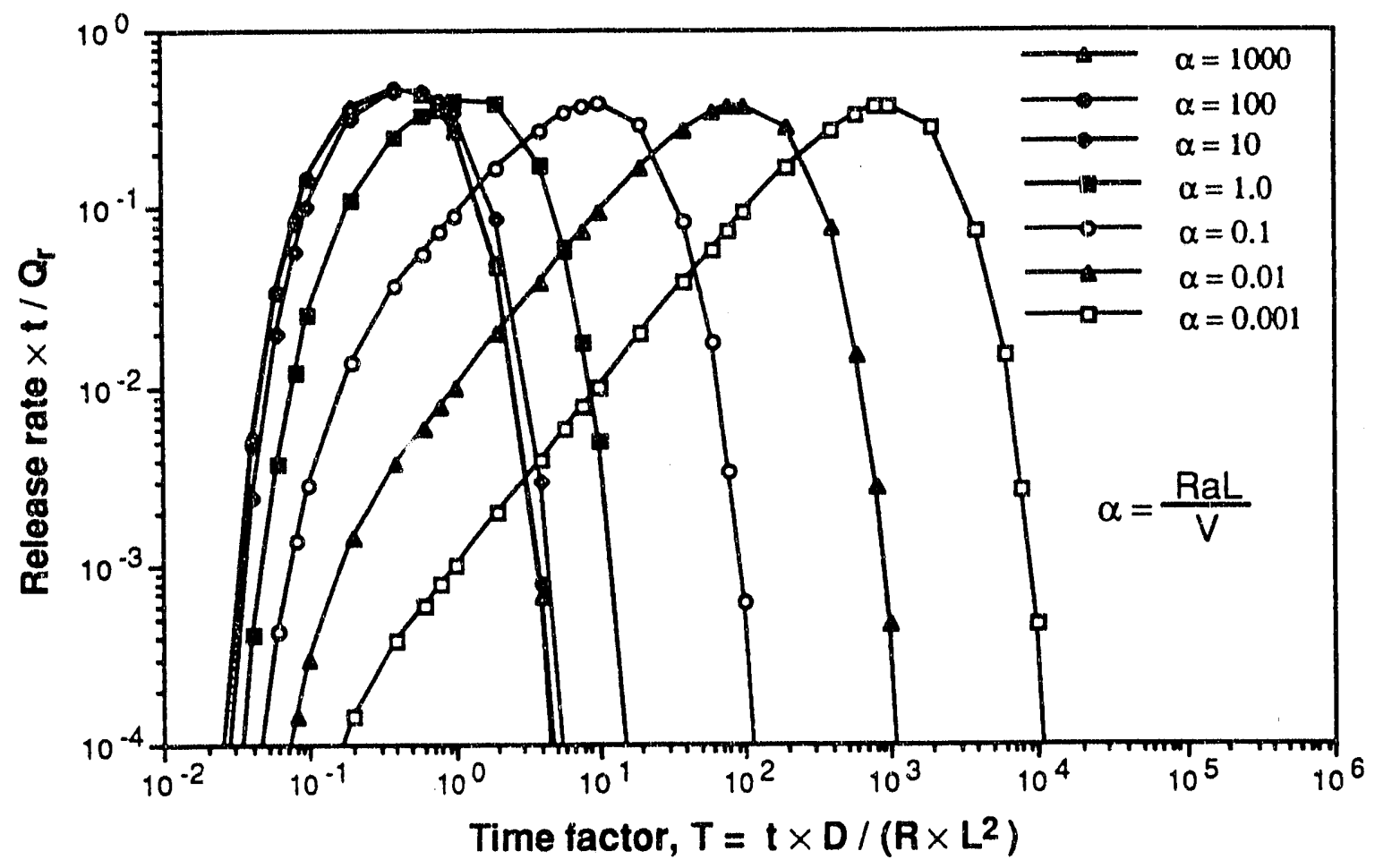

Figure 3. Pulse rapid release versus dimensionless parameters

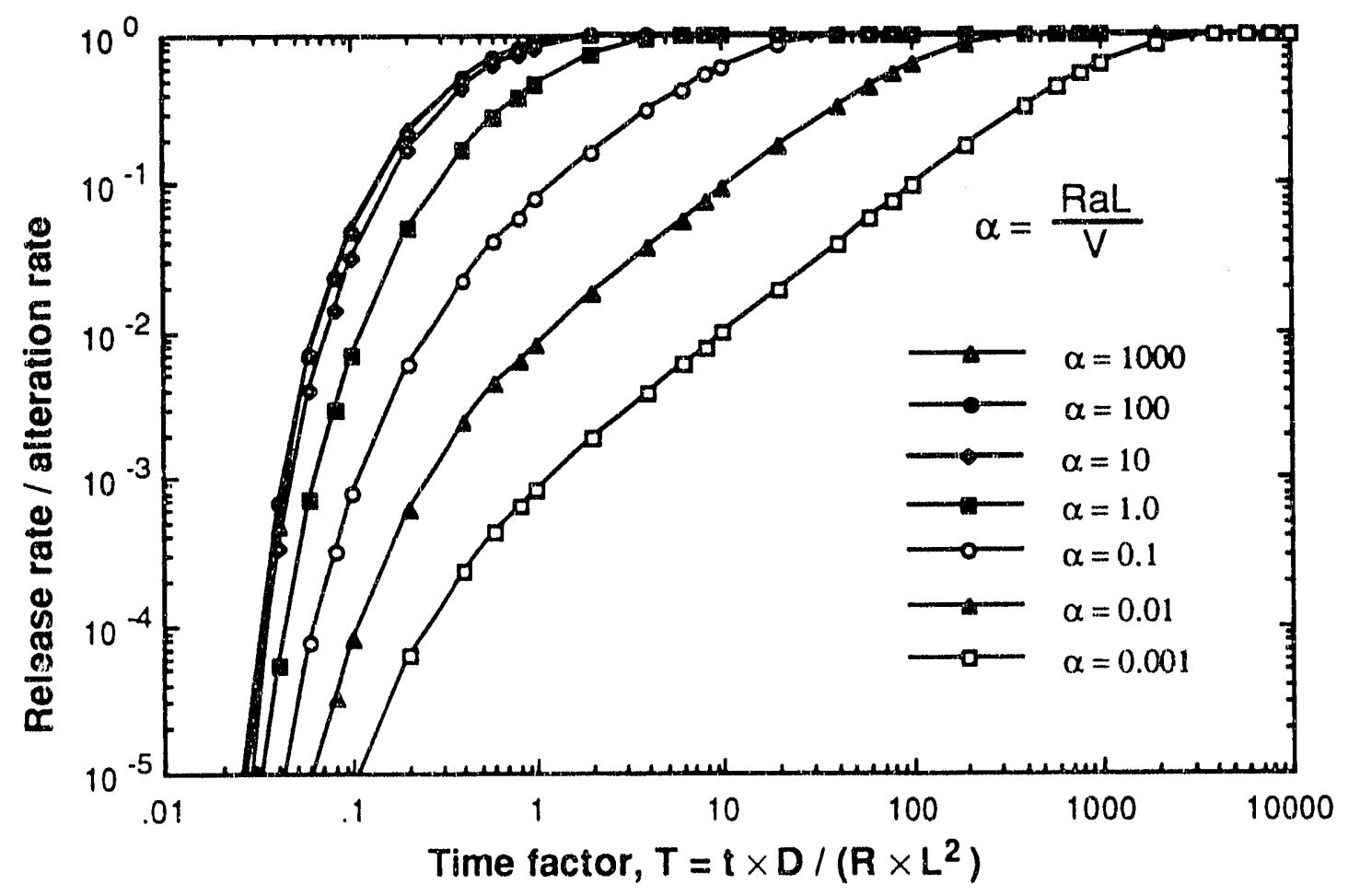

Figure 4. Waste-matrix alteration-controlled release versus dimensionless parameters. 
the alteration-controlled release as the time when the release rate reaches, say, $10 \%$ of the alteration rate of the waste-matrix, then according to Fig. 4 , at $10 \%$ fractional release rate,

$$
\begin{aligned}
& T \approx 0.14, \text { or } t_{b}=0.14 \frac{R^{2}}{D} \text { for large values of } \alpha, \text { and } \\
& T \approx \frac{0.1}{\alpha}, \text { or } t_{b}=0.1 \frac{V L}{D a} \text { for small values of } \alpha .
\end{aligned}
$$

\section{TWO DIFFUSIVE BARRIER ANALYSIS}

In order to consider the conditions when there is an additional barrier, such as the container skin with cracks (Fig. 5a), or when the difference of diffusion resistance between the rubble zone and the host rock is not great, for example, high degree of saturation in the rubble bed (Fig. 5b), solutions of diffusion release for two diffusion resistant zones of finite thicknesses are developed.

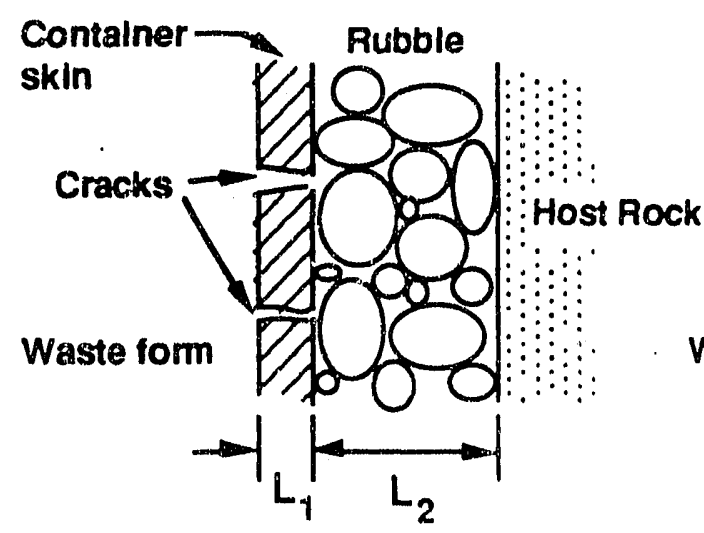

(a)

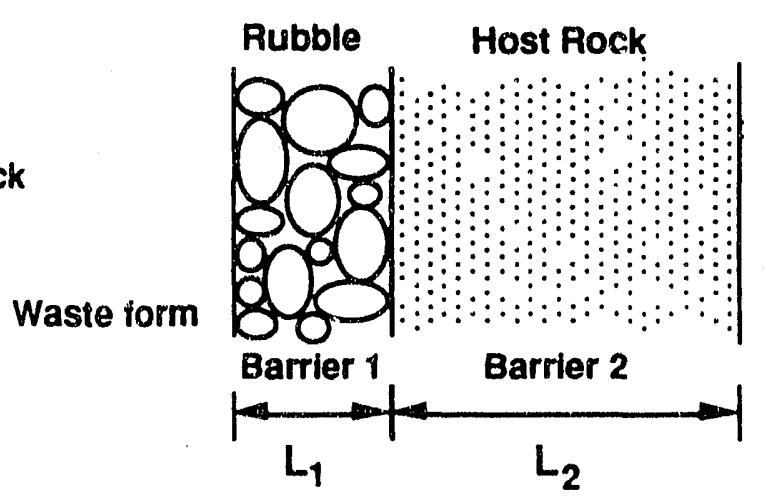

(b)

Figure 5. Two diffusive barriers for radionuclide release from waste package.

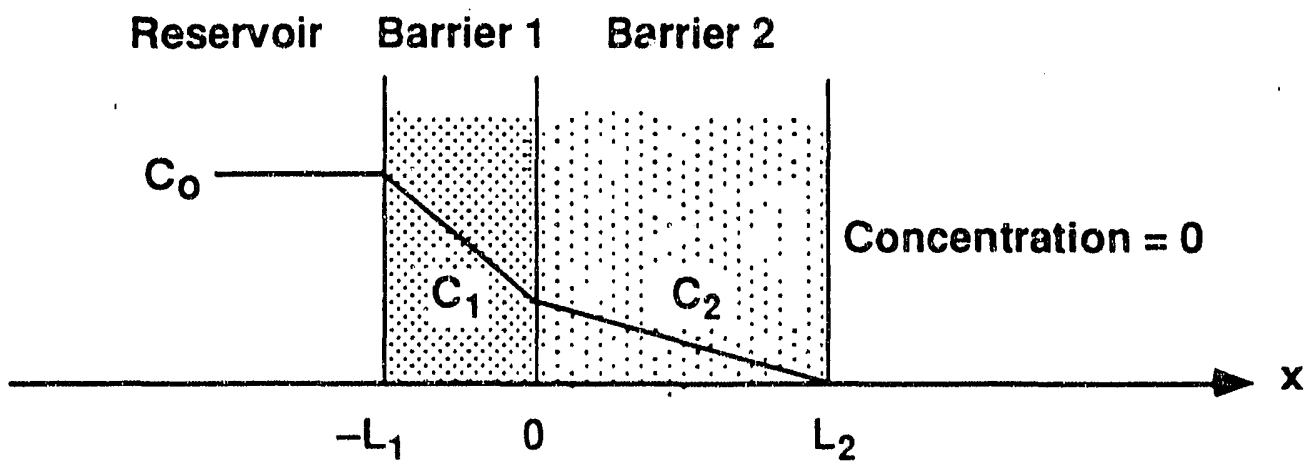

Figure 6. One-dimensional two-barrier diffusion analysis 
The problem can be represented by a planar one-dimensional two-zone problem as shown in Fig. 6. The basic diffusion equations for a one-dimensional two-zone problem are:

$$
\begin{array}{ll}
R_{1} \frac{\partial C_{1}(x, t)}{\partial t}=D_{1} \frac{\partial^{2} C_{1}(x, t)}{\partial x^{2}}, & t>0, \quad-L_{1}<x<0 \\
R_{2} \frac{\partial C_{2}(x, t)}{\partial t}=D_{2} \frac{\partial^{2} C_{2}(x, t)}{\partial x^{2}}, & t>0, \quad 0<x<L_{2}
\end{array}
$$

where the subscripts of 1 and 2 indicate the properties related to barriers 1 and 2 , respectively. The solutions of problems for the following three cases of radionuclide sources can be obtained by taking Laplace transform with respect to $t$, and using the expansion theorem for the inversion of Laplace transform.

\section{Constant Concentration Source}

For radionuclides of a limited solubility at a constant concentration, $\mathrm{C}_{\mathrm{s}}$, the initial and boundary conditions are

$$
\begin{array}{ll}
C_{1}(x, 0)=C_{2}(x, 0)=0, & -L_{1}<x<L_{2} \\
C_{1}\left(-L_{1}, t\right)=C_{0}=C_{s}, & t \geq 0 \\
C_{2}\left(L_{2}, t\right)=0, & t \geq 0 \\
C_{1}(0, t)=C_{2}(0, t), & t \geq 0 \\
-a_{1} D_{1} \frac{\partial C_{1}}{\partial x}=-a_{2} D_{2} \frac{\partial C_{2}}{\partial x}, & \text { at } x=0, t \geq 0
\end{array}
$$

where $a_{1}$ and $a_{2}$ are areas for diffusion in barriers 1 and 2 , respectively. Taking a Laplace transform with respect to $t$, and using a similar method as in the one-barrier transient-pulse diffusion problem as shown in the Appendix, we obtain the following solutions for the mass release rates.

At borehole wall, $x=0$,

$$
f_{c}=a_{1} D_{1} C_{s}\left[\frac{1}{\beta L_{2}+L_{1}}-\sum_{n=1}^{\infty} \frac{2 \delta \sin \left(\omega_{1} \mu_{n}\right) \sin \left(\omega_{2} \mu_{n}\right) \cos \left(\omega_{2} \mu_{n}\right)}{\beta L_{1} \sin ^{2}\left(\omega_{2} \mu_{n}\right)+\delta^{2} L_{2} \sin ^{2}\left(\omega_{1} \mu_{n}\right)} e^{-\mu_{n}^{2} t}\right]
$$

and at the outer boundary of barrier $2, x=L_{2}$,

$$
f_{c}=a_{1} D_{1} C_{s}\left[\frac{1}{\beta L_{2}+L_{1}}-\sum_{n=1}^{\infty} \frac{2 \delta \sin \left(\omega_{1} \mu_{n}\right) \sin \left(\omega_{2} \mu_{n}\right)}{\beta L_{1} \sin ^{2}\left(\omega_{2} \mu_{n}\right)+\delta^{2} L_{2} \sin ^{2}\left(\omega_{1} \mu_{n}\right)} e^{-\mu_{n}^{2} t}\right]
$$


where $\beta=\frac{a_{1} D_{1}}{a_{2} D_{2}}$

$$
\begin{aligned}
& \delta=\sqrt{\frac{D_{1} R_{2}}{D_{2} R_{1}}}, \\
& \omega_{1}=L_{1} \sqrt{R_{1} / D_{1}}, \\
& \omega_{2}=L_{2} \sqrt{R_{2} / D_{2}}, \text { and } \\
& \mu_{n}=\text { nth root of the characteristic equation, } \\
& \quad \beta \cot \left(\omega_{1} \mu\right)=\delta \cot \left(\omega_{2} \mu\right)
\end{aligned}
$$

\section{Transient Pulse Source}

For a pulse rapid release of radionuclides, $Q_{r}$, into the volume of water in the container, $V$, the initial and boundary conditions are

$$
\begin{array}{ll}
C_{1}\left(-L_{1}, 0\right)=C_{0}=\frac{Q_{r}}{V}, & \\
C_{1}(x, 0)=C_{2}(x, 0)=0, & -L_{1}<x \leq L_{2} \\
C_{2}\left(L_{2}, t\right)=0, & t \geq 0 \\
C_{1}(0, t)=C_{2}(0, t), & t \geq 0 \\
-a_{1} D_{1} \frac{\partial C_{1}}{\partial x}=-a_{2} D_{2} \frac{\partial C_{2}}{\partial x}, & \text { at } x=0, t \geq 0 \\
-V \frac{\partial C_{1}}{\partial t}=-a_{1} D_{1} \frac{\partial C_{1}}{\partial x}, & \text { at } x=-L_{1}, t>0
\end{array}
$$

Similarly, according to the same method as for the one-barrier diffusion problem shown in the Appendix, the solutions for the mass release rates are:

$$
\begin{aligned}
& f_{r}=2 \alpha_{1} Q_{r} \sum_{n=1}^{\infty} \frac{\mu_{n} \cot \left(\omega_{2} \mu_{n}\right)}{\psi} e^{-\mu_{n}^{2} t} \text {, at borehole wall, } x=0 \text {, and } \\
& f_{r}=2 \alpha_{1} Q_{r} \sum_{n=1}^{\infty} \frac{\mu_{n}}{\psi \sin \left(\omega_{2} \mu_{n}\right)} e^{-\mu_{n}^{2} t}, \text { at outer boundary, } x=L_{2}
\end{aligned}
$$

where $\psi=\sin \left(\omega_{2} \mu_{n}\right)\left\{\gamma\left[\cot \left(\omega_{1} \mu_{n}\right)-\omega_{1} \mu_{n} \csc ^{2}\left(\omega_{1} \mu_{n}\right)\right]+\omega_{2} \csc ^{2}\left(\omega_{2} \mu_{n}\right)\left[\alpha_{1} \cot \left(\omega_{1} \mu_{n}\right)-\mu_{n}\right]\right.$ $\left.+\cot \left(\omega_{2} \mu_{n}\right)\left[\alpha_{1} \omega_{1} \csc ^{2}\left(\omega_{1} \mu_{n}\right)+1\right]\right\}$ 


$$
\begin{aligned}
& \alpha_{1}=\frac{a_{1} \sqrt{D_{1}} \overline{R_{1}}}{V} \\
& \gamma=\frac{a_{1} \sqrt{D_{1} R_{1}}}{a_{2} \sqrt{D_{2} R_{2}}} \\
& \omega_{1}=L_{1} \sqrt{R_{1} / D_{1}}, \\
& \omega_{2}=L_{2} \sqrt{R_{2} / D_{2}}, \text { and } \\
& I^{\prime \prime}=n t h \operatorname{root} \text { of the characteristic equation, } \\
& \mu=\frac{\alpha_{1}\left[\cot \left(\omega_{1} \mu\right) \cot \left(\omega_{2} \mu\right)-\gamma\right]}{\gamma \cot \left(\omega_{1} \mu\right)+\cot \left(\omega_{2} \mu\right)}
\end{aligned}
$$

\section{Steady Source Congruent with Waste-matrix Alteration}

For waste-matrix alteration-controlied release of radionuclides with a mass alteration rate of $q_{a}$, similar to one-zone problem, the mass release rates are obtained by a time convolution of the pulse rapid release [Eqs. (13a) and (13b)] with a pulse input of $\mathrm{qa} d \tau$.

For $\mathrm{t} \leq \mathrm{t}_{\mathrm{e}}$

$$
\begin{aligned}
& f_{a}=2 \alpha_{1} q_{a} \int_{0}^{t} \sum_{n=1}^{\infty} \frac{\mu_{n} \cot \left(\operatorname{in} 2 \mu_{n}\right)}{\psi} e^{-\mu_{n}^{2}(t-\tau)} d \tau \\
& =2 \alpha_{1} q_{a} \sum_{n=1}^{\infty} \frac{\cot \left(\omega_{2} \mu_{n}\right)}{\psi \mu_{n}}\left(1-e^{-\mu_{n}^{2} t}\right), \text { at borehole wall, and } \\
& f_{a}=2 \alpha_{1} q_{a} \int_{0}^{t} \sum_{n=1}^{\infty} \frac{\mu_{n}}{\psi \sin \left(\omega_{2} \mu_{n}\right)} e^{-\mu_{n}^{2}(t-\tau)} d \tau \\
& =2 \alpha_{1} q_{a} \sum_{n=1}^{\infty} \frac{1}{\psi \mu_{n} \sin \left(\omega_{2} \mu_{n}\right)}\left(1-e^{-\mu_{n}^{2} t}\right) \text {, at outer boundary }
\end{aligned}
$$


For $t \geq t_{e}$

$$
\begin{aligned}
f_{a} & =2 \alpha_{1} q_{a} \int_{0}^{t_{e}} \sum_{n=1}^{\infty} \frac{\mu_{n} \cot \left(\omega_{2} \mu_{n}\right)}{\psi} e^{-\mu_{n}^{2}(t-\tau)} d \tau \\
& =2 \alpha_{1} q_{a} \sum_{n=1}^{\infty} \frac{\cot \left(\omega_{2} \mu_{n}\right)}{\psi \mu_{n}}\left[e^{-\mu_{n}^{2}\left(t-t_{e}\right)}-e^{\left.-\mu_{n}^{2} t\right]}\right. \text {, at borehole wall, and } \\
f_{a} & =2 \alpha_{1} q_{a} \int_{n=1}^{t_{e}} \frac{\mu_{n}}{\psi \sin \left(\omega_{2} \mu_{n}\right)} e^{-\mu_{n}^{2}(t-\tau)} d \tau \\
& =2 \alpha_{1} q_{a} \sum_{n=1}^{\infty} \frac{e^{-\mu_{n}^{2}\left(t-t_{e}\right)}-e^{-\mu_{n}^{2} t}}{\psi \mu_{n} \sin \left(\omega_{2} \mu_{n}\right)}, \text { at outer boundary }
\end{aligned}
$$

The solutions in Eqs. (13) - (18) are also in the form of a series of algebraic elements. Thus, parameter and sensitivity studies can be conducted according to these solutions for two-barrier diffusion problems.

\section{COMPARISON OF COMPUTATION RESULTS}

Numerical computations were performed to obtain the diffusive release from the waste package in order to provide some points of comparison with results obtained by others, and to compare our one-zone and two-zone analyses in a case where they should be similar.

Theoretically, in the computations, the rnore the number of the summation terms of the series in these solutions, the more accurate results we can get. For one-barrier diffusive problems, the minimum summation terms depend on $T=D t / R L^{2}$. The smaller the value of $T$, the more summation terms are needed. Generally, for the onebarrier diffusive release, rather accurate results can be obtained with no more than 50 summation terms. For two-barrier diffusive problems, besides depending on the values of $\omega_{1}, \omega_{2}$ and $t$, the number of summation terms must be at least greater than the larger of $\omega_{1} / \omega_{2}$ or $\omega_{2} / \omega_{1}$, so that reasonably accurate results can be obtained. In the present computations, 500 summation terms are used. It should be noted that in finding the roots of the characteristic equations (Eqs 4, 14, and 16), it is important to include all possible roots within the range of interest in order to secure the correct results.

Our results of two-zone problems are compared to Kang's solutions for one finite backfill zone and one host rock zone of semi-infinite extent. ${ }^{6}$ The pulse-input diffusive 
release at the borehole wall was computed for various properties of backfill, using the parameter values in Table 1.

Table 1. Parameters Used in Comparisons with Kang's Results

\begin{tabular}{|l|c|c|}
\hline \multicolumn{1}{|c|}{ Parameters } & Barrier 1 & Barrier 2 \\
\hline Area for diffusion $\left(\mathrm{m}^{2}\right)$ & 1.83 & 0.61 \\
\hline Diffusion Coefficient $\left(\mathrm{cm}^{2} / \mathrm{s}\right)$ & $10^{-5}$ & $10^{-5}$ \\
\hline Retardation Coefficient & 1,10, and 100 & 1 and 100 \\
\hline Thickness $(\mathrm{m})$ & $0,0.15,0.3$, and 0.6 & 10.0 \\
\hline Pulse Release Fraction & \multicolumn{2}{|c|}{0.01} \\
\hline Container Water Volume $\left(\mathrm{m}^{3}\right)$ & \multicolumn{2}{|c|}{0.45} \\
\hline
\end{tabular}

Fig. 7 shows our result for materials of low retardation agrees very well with Kang's answer using numerical inversion of Laplace transform, which is considered more accurate than his approximate solution. There are also very good agreements between the release rates obtained in our computations and those in Kang's solutions for various backfill thicknesses (Fig. 8) and for different retardation coefficients of the barriers (Fig. 9). Small differences exist at a very large time since we consider a finite thickness of host rock while an infinite extent of rock was considered in Kang's computations. These differences are not of importance because they occur at a very large time when the release rates are usually many orders of magnitude below the peak release rates.

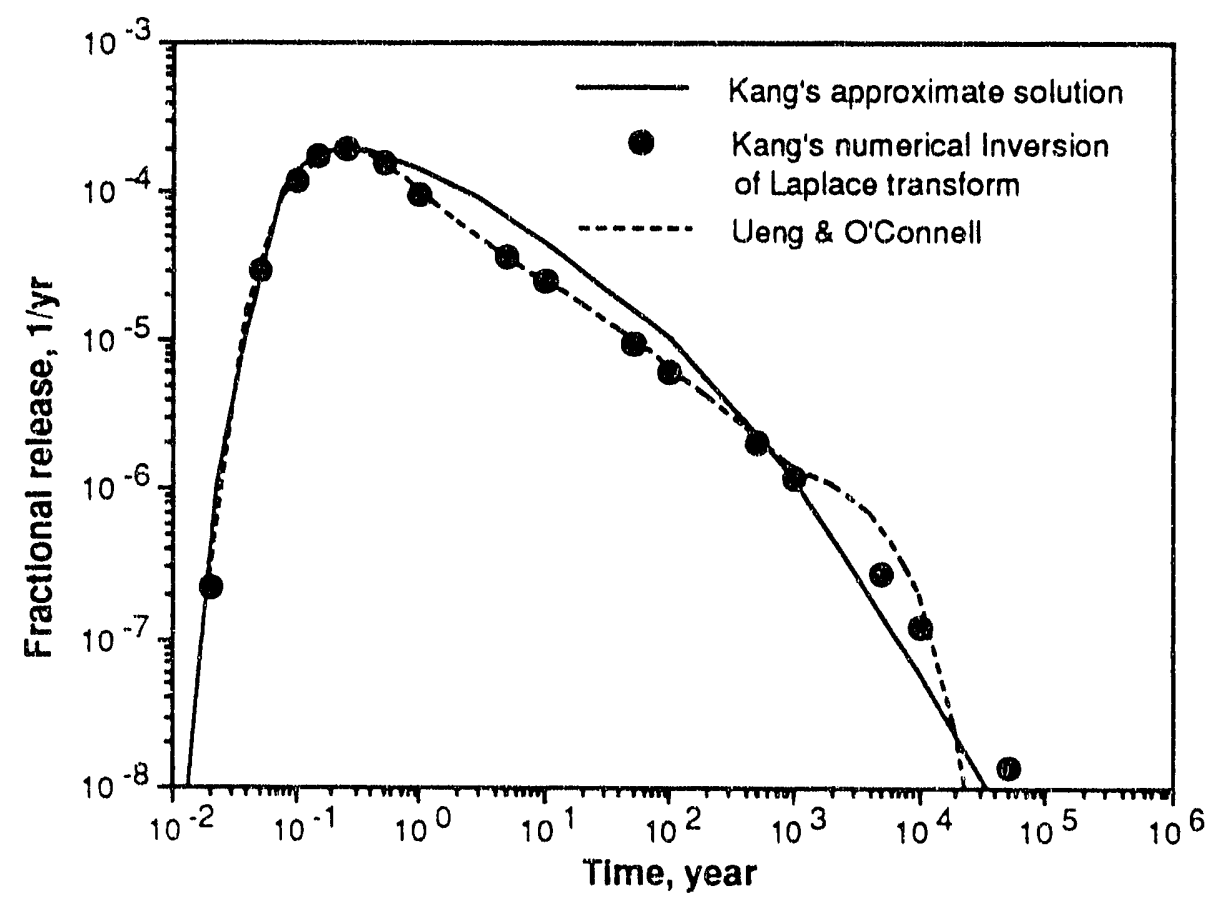

Figure 7. Comparison of pulse release by various solutions, $R_{1}=R_{2}=1.0$. 


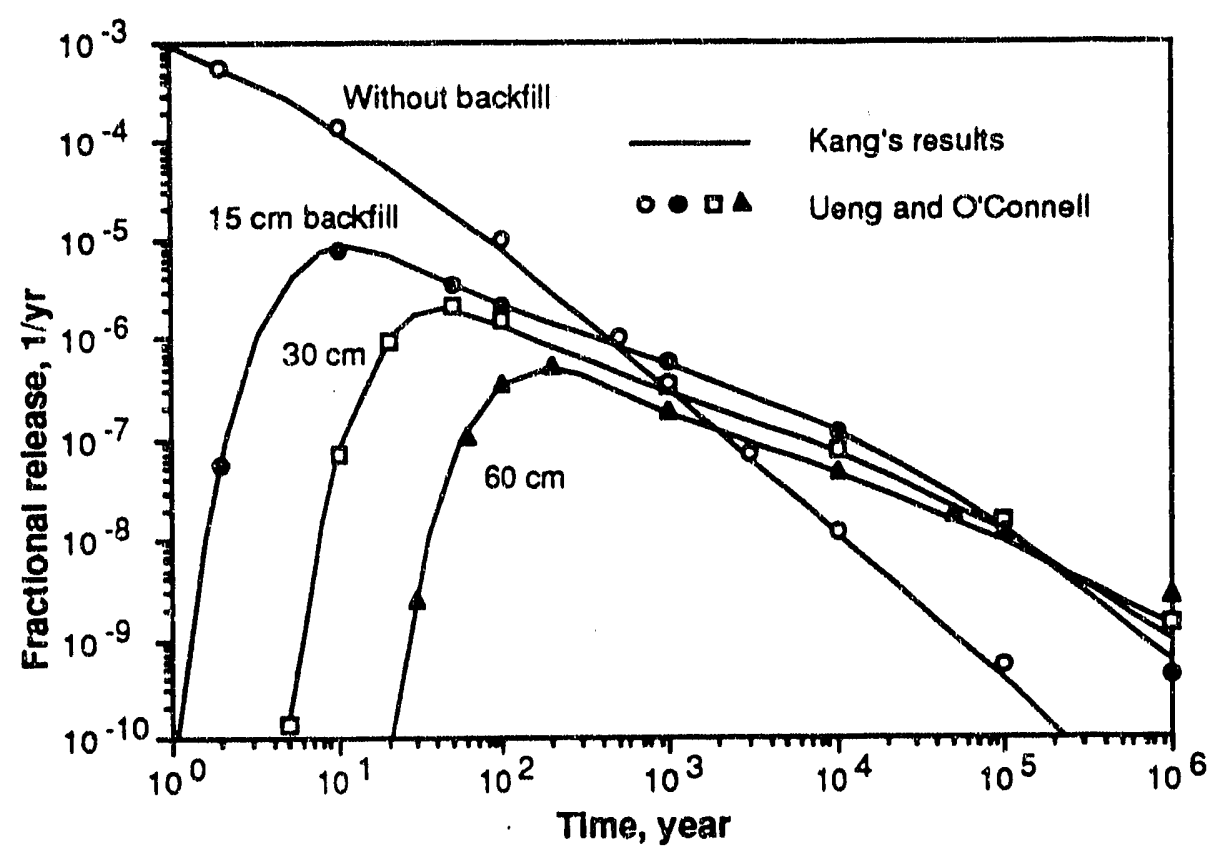

Figure 8. Comparison of releases for various backfill thicknesses

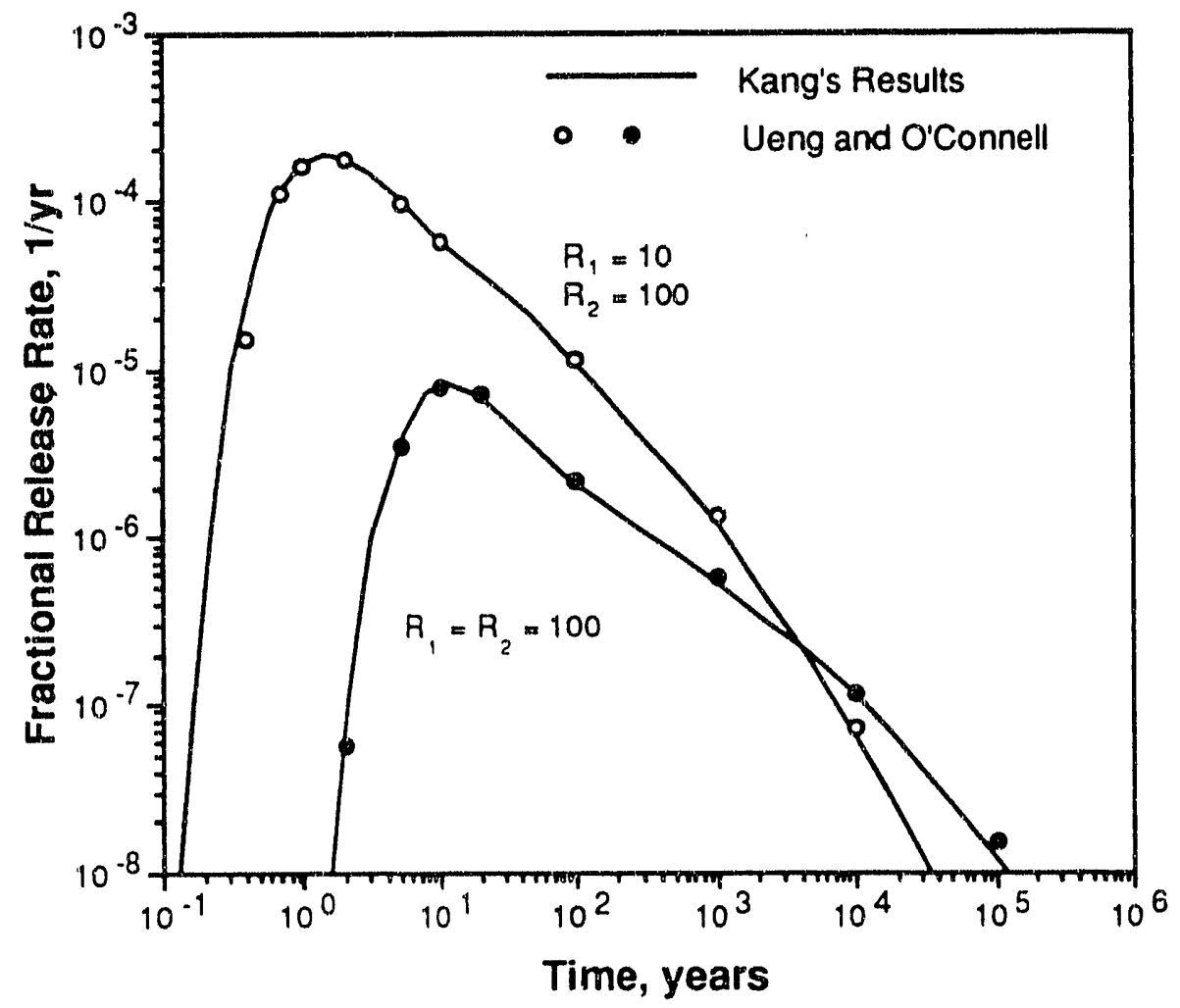

Figure 9. Comparison of pulse releases for various backfill retardation coefficients in a two-barrier system. 
Comparisons were also made between the release rates from the waste package reported in the 1990 Working Group 2 Report $^{8}$ and those computed according to our solutions in this paper for I-129 and Cs-135. This case has a diffusion coefficient $10^{3}$ times smaller in the rubble zone, and was modeled with both our one-zone and twozone models. The values of the parameters used are given in Table 2. Figure 10 shows the comparisons. Both our solutions agree well with each other and with those in Ref. 8. The one-zone result departs at later times, low in the tail of the release curve. However, since we are more interested in the peak release rate, a sufficiently good approximation can be obtained based on the simplified one-zone diffusive model.

Table 2. Parameters Used in Comparison with 1990 WG2 Report

\begin{tabular}{|c|c|c|c|}
\hline \multicolumn{2}{|c|}{ Parameters } & Rubble Zone & Host Rock \\
\hline \multicolumn{2}{|l|}{ Area for Diffusion $\left(\mathrm{m}^{2}\right)$} & 1.0 & 1.0 \\
\hline \multicolumn{2}{|c|}{ Diffusion Coefficient $\left(\mathrm{cm}^{2} / \mathrm{s}\right)$} & $10^{-8}$ & $10^{-5}$ \\
\hline \multirow[t]{2}{*}{ Retardation Coefficient } & $\mathrm{I}-129$ & 1.0 & 1.0 \\
\hline & Cs-135 & 610 & 610 \\
\hline \multicolumn{2}{|l|}{ Thickness (m) } & 0.30 & 10.0 \\
\hline \multicolumn{2}{|l|}{ Rapid Release Fraction } & \multicolumn{2}{|c|}{$\frac{1}{0.02}$} \\
\hline \multicolumn{2}{|l|}{ Waste Package Internal } & \multicolumn{2}{|c|}{1.22} \\
\hline
\end{tabular}

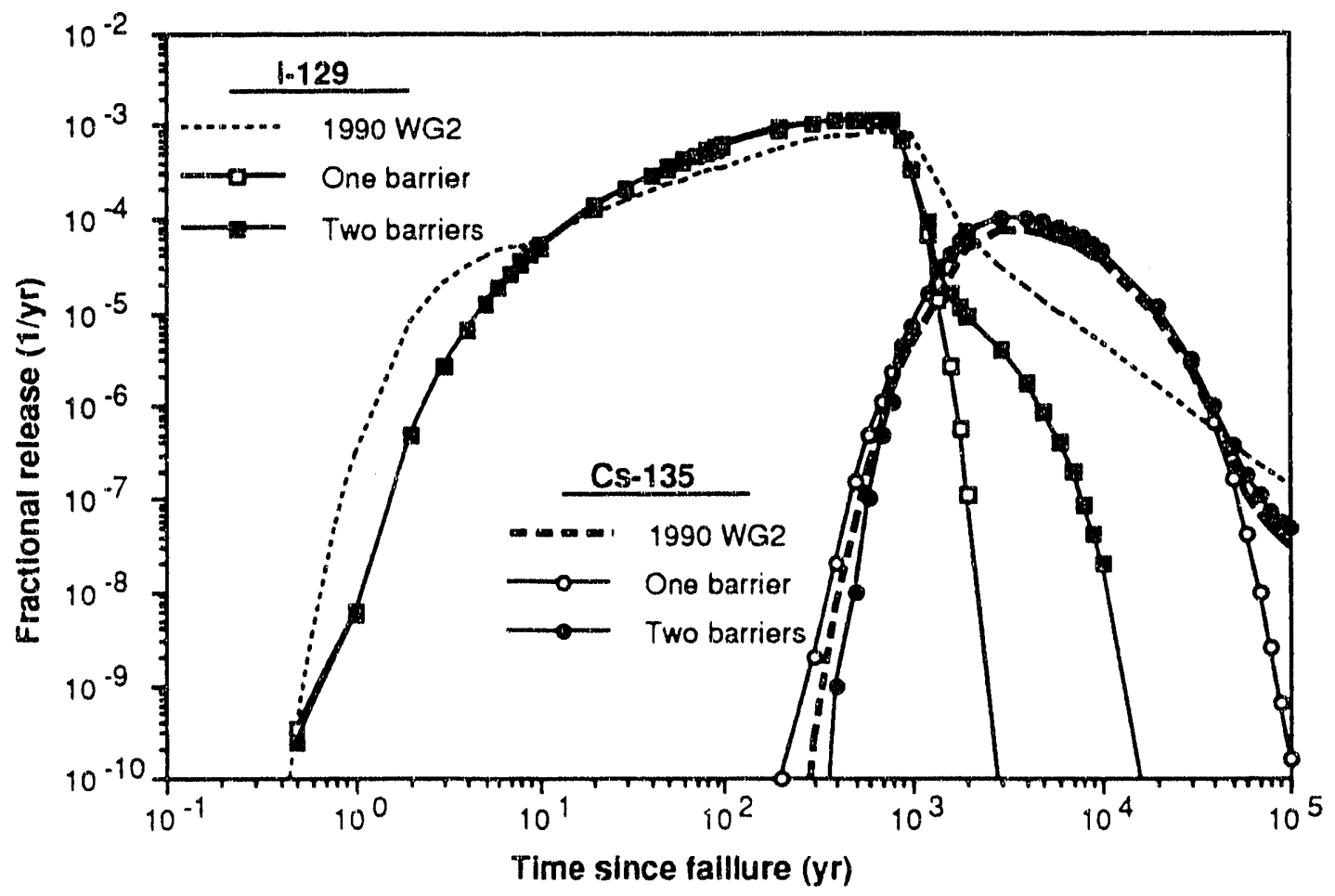

Figure 10. Comparison of radionuclide releases from spent fuel waste package. 


\section{CONCLUSIONS}

The diffusive releases of radionuclides from the waste package were approximated by one-dimensional one- and two-diffusive-barrier problems. The solutions of these problems were developed in series form consisting of algebraic elements, so that parameters can be identified in sensitivity studies. Development of our one- and two-zone solutions and earlier semi-infinite zone solutions by others allows checks among them. Comparison in the preceding section with an extensive selection of published analyses supports verification of our solutions and applications.

The one-dimensional one-barrier system is a good approximation for the diffusive release through an unsaturated rubble zone having much lower diffusivity than the surrounding host rock. This is verified with the solutions of one-dimensional two-barrier problems. Two dimensionless parameters, $T=D t / R L^{2}$ and $\alpha=a L R / V$, are introduced to facilitate the parameter and sensitivity studies. The parameter study can identify the key parameters for high- and low-retardation radionuclides, and the ranges of parameter values needed if a rubble barrier is to be effective.

\section{ACKNOWLEDGMENTS}

The authors wish to thank Dr. Ananda Wijesinghe for his help in the mathematical derivations, and Dr. John Nitao for his review of this report.

\section{REFERENCES}

1. U. S. Nuclear Regulatory Commission, "Disposal of High-Level Radioactive Wastes in Geologic Repositories," 10 Code of Federal Regulations, Part 60, 1991. (Readily Available)

2. Conca, J. L., "Diffusion Barrier Transport Properties of Unsaturated Paintbrush Tuff Rubble Backfill," Proceedings of the International High-Level Waste Management Conference, Las Vegas, NV, p. 394, 1990. NNA.900710.0198

3. Apted, M. J. and D. W. Engel, "Mass Transfer Analysis of Waste Packages Containing Defense Waste Processing Facility Glass as a Waste Form," Proceedings of the International High-Level Waste Management Conference, Las Vegas, NV, p. 388, 1990. NNA.920121.0012

4. Pigford, T. H. and P. L. Chambré, "Near-Field Mass Transfer in Geologic Disposal Systems: a Review," Scientific Basis for Nuclear Waste Management XI, eds. M.J. Apted and R.E. Westerman, Materials Research Society, pp. 12.5-141, 1988. (Readily Available)

5. Pigford T. H., P. L. Chambré and W. W.-L. Lee, A Review of Near-Field Mass Transfer in Geologic Disposal Systems, Report LBL-27045, 1990. NNA.920121.0009 
6. Kang, C. H., Mass Transfer and Transport of Radionuclides Through Backfill in a Geologic Nuclear Waste Repository, Ph.D. Dissertation, Department of Nuclear Engineering, University of California, Berkeley, CA, 1989. NNA.920121.0010

7. Lee, W. W.-L. and T. H. Pigford, "Release Rate of Soluble Species at Yucca Mountain," Proceedings, Nuclear Waste Isolation in the Unsaturated Zone-Focus '89, Las Vegas, NV, pp. 281-287, 1989. NNA.920121.0013

8. Apted, M. J., W. J. O'Connell, K. H. Lee, A. T. Macintyre, T.-S. Ueng, T. H. Pigford and W. W.-L. Lee, "Preliminary Calculations of Release Rates From Spent Fuel in a Tuff Repository," Proceedings, 2nd International High-Level Waste Management Conference, Las Vegas, NV, Vol. 2, pp. 1080-1090, 1991. NNA.920121.0011 
APPENDIX - Derivation of Solutions for One-barrier Diffusion of a Transient Pulse Source

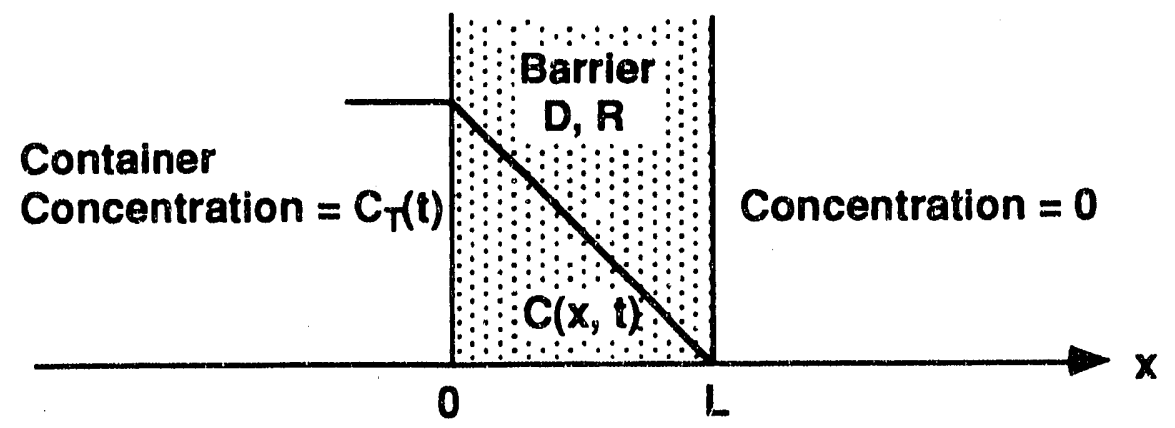

Figure A-1. One-dimensional one-barrier diffusion system

The governing equation for the one-dimensional one-barrier diffusion problem as shown in Fig. A-1 is:

$$
R \frac{\partial C(x, t)}{\partial t}=D \frac{\partial^{2} C(x, t)}{\partial x^{2}}, t>0,0<x<L
$$

The initial and boundary conditions for the one-barrier diffusion with a transient pulse source are:

$$
\begin{array}{ll}
C(x, t)=0, & t=0,0<x<L, \\
C(x, t)=0, & t>0, x=L, \\
C(x, t)=C_{T}(t), & t \geq 0, x=0, \text { and } \\
C(0,0)=C_{T}(0)=C_{0}, t=0 .
\end{array}
$$

In addition the mass balance relation equates the mass change rate in the container and the mass flux through the inner surface of the barrier:

$$
V \frac{\partial C(x, t)}{\partial t}=D a \frac{\partial C(x, t)}{\partial x}, x=0, t>0
$$

Take a Laplace transform of Eq. (A-1) with respect to $t$,

$$
s \tilde{C}(x, s)-C(x, 0)=\frac{D}{R} \frac{d^{2} \tilde{C}(x, s)}{d x^{2}}
$$

where $\tilde{C}(x, s)$ is the Laplace transform of $C(x, t)$, i.e.,

$$
\tilde{C}(x, s)=\int_{0}^{\infty} e^{-s t} C(x, t) d t
$$


Since $C(x, 0)=0$ for $x>0$ according to the initial condition, Eq. (A-2), then

$$
s \tilde{C}(x, s)=\frac{D}{R} \frac{d^{2} \tilde{C}(x, s)}{d x^{2}}
$$

The solution of Eq. (A-8) is:

$$
\tilde{C}(x, s)=A \cosh \left(\sqrt{\frac{s R}{D}} x\right)+B \sinh \left(\sqrt{\frac{s R}{D}} x\right)
$$

Considering the boundary conditions, Eqs. (A-3) and (A-4), we obtain

$$
\tilde{C}(x, s)=\tilde{C}_{T}(s)\left[\cosh \left(\sqrt{\frac{s R}{D}} x\right)-\operatorname{coth}\left(\sqrt{\frac{s R}{D}} L\right) \sinh \left(\sqrt{\frac{s R}{D}} x\right)\right]
$$

Take a Laplace transform of Eq. (A-6),

$$
s \tilde{C}_{T}(s)-C(0,0)=\frac{a D}{V}\left(\frac{d \tilde{C}(x, s)}{d x}\right)_{x=0}
$$

Substituting Eqs. (A-5) and (A-9) into Eq. (A-10) and rearranging the equation, we obtain

$$
\tilde{C}_{T}(s)=\frac{C_{o}}{s+\frac{a D}{V} \sqrt{\frac{s R}{D}} \operatorname{coth}\left(\sqrt{\frac{s R}{D}} L\right)}
$$

Therefore, Eq. (A-9) becomes

$$
\tilde{C}(x, s)=\frac{C_{0}\left[\cosh \left(\sqrt{\frac{s R}{D}} x\right)-\operatorname{coth}\left(\sqrt{\frac{s R}{D}} L\right) \sinh \left(\sqrt{\frac{s R}{D}} x\right)\right]}{s+\frac{a D}{V} \sqrt{\frac{s R}{D}} \operatorname{coth}\left(\sqrt{\frac{s R}{D}} L\right)}=\frac{\Psi(s)}{\phi(s)}
$$

Since $\phi(s)$ and $\Psi(s)$ can be expressed in polynomial series in s, we can use the expansion theorem to obtain the inversion of $\tilde{C}(x, s)$, i.e.,

$$
C(x, \hat{t})=\sum_{n} \frac{\Psi\left(s_{n}\right)}{\phi^{\prime}\left(s_{n}\right)} e^{s_{n} t}
$$


where $s_{n}$ are roots of Eq. $(A-14)$ :

$$
\phi(s)=s+\frac{a D}{V} \sqrt{\frac{s R}{D}} \operatorname{coth}\left(\sqrt{\frac{s R}{D}} L\right)=s+\frac{a D i}{V} \sqrt{\frac{s R}{D}} \cot \left(i \sqrt{\frac{s R}{D}} L\right)=0,
$$

and

$$
\phi^{\prime}\left(s_{n}\right)=\left.\frac{d \phi(s)}{d s}\right|_{s=s_{n}}
$$

where $i=\sqrt{-1}$.

$$
\begin{aligned}
& \text { Let } \mu=i \sqrt{\frac{s \bar{R}}{D}} L \text {, so that } s=-\frac{\mu^{2} D}{R L^{2}} \text {, and rearrange Eq. }(A-14) \text {, then } \\
& -\mu^{2}+\alpha \mu \cot \mu=0,
\end{aligned}
$$

where $\alpha=\frac{\operatorname{RaL}}{\mathrm{V}}$. That is,

$$
\begin{aligned}
& \mu=0, \text { or } \\
& \mu=\alpha \cot \mu
\end{aligned}
$$

$\mu=0$, or $s=0$, is not a root of Eq. (A-14). Eq. (A-16) has an infinite number of roots, $\mu_{n}$, $n=1,2, \ldots$, and $s_{n}=-\frac{\mu_{n}^{2} D}{R L^{2}}$. Then,

$$
\begin{aligned}
\phi^{\prime}\left(s_{n}\right) & =1+\frac{a D}{V}\left[\sqrt{\frac{R}{D}} \frac{i}{2 \sqrt{s_{n}}} \cot \mu_{n}-i \sqrt{\frac{s_{n} R}{D}}\left(\csc ^{2} \mu_{n}\right)\left(i \sqrt{\frac{R}{D}} \frac{L}{2 \sqrt{s_{n}}}\right)\right] \\
& =1+\frac{\alpha}{2}\left(\csc ^{2} \mu_{n}-\frac{\cot \mu_{n}}{\mu_{n}}\right) \\
& =\frac{1}{2}\left(1+\alpha+\frac{\mu_{n}^{2}}{\alpha}\right)
\end{aligned}
$$

Hence, substituting $\phi^{\prime}\left(s_{n}\right)$ into Eq. (A-13), we obtain

$$
C(x, t)=2 C_{0} \sum_{n=1}^{\infty} \frac{\cos \left(\frac{\mu_{n} x}{L}\right)-\frac{\mu_{n}}{\alpha} \sin \left(\frac{\mu_{n} x}{L}\right)}{1+\alpha+\frac{\mu_{n}^{2}}{\alpha}} e^{-\left(\mu_{n}^{2} D / R L^{2}\right) t}
$$


The mass diffusion release rate at the outer boundary of the barrier is

$$
f_{r}(t)=-a D\left(\frac{d C(x, t)}{d x}\right)_{x=L}
$$

Taking the derivative of Eq. (A-17) and using Eq. (A-16), we obtain

$$
f_{r}(t)=\frac{2 a D C_{0}}{L} \sum_{n=1}^{\infty} \frac{\mu_{n}}{\sin \mu_{n}\left(1+\alpha+\mu_{n}^{2} / \alpha\right)} e^{-\mu_{n}^{2} D t / R L^{2}}
$$


The following number is for Office of Civilian Radioactive Waste Management Records Management purposes only and should not be used when ordering this document: 

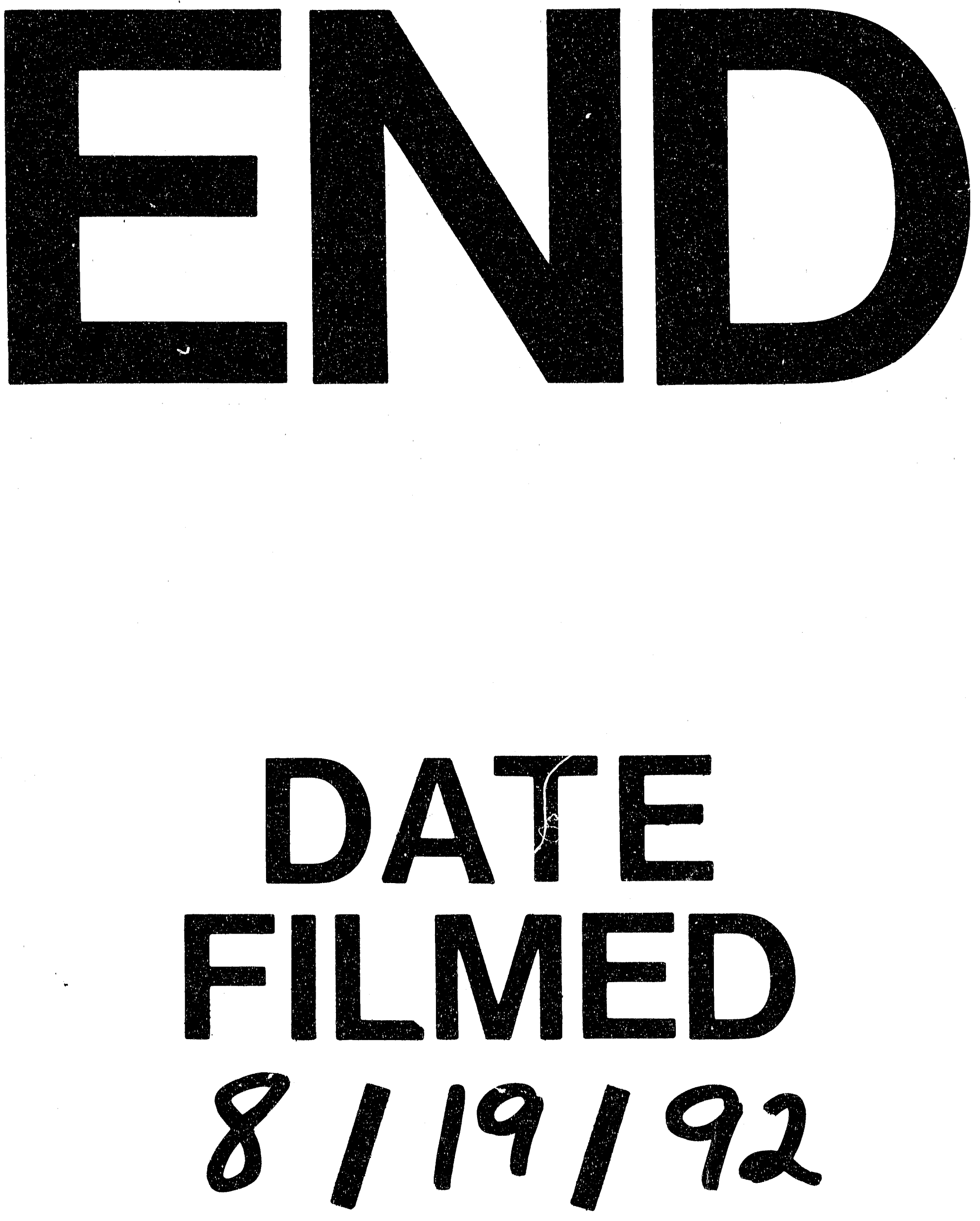

1 
